\title{
Estimates of daily net endogenous acid production in the elderly UK population: analysis of the National Diet and Nutrition Survey (NDNS) of British adults aged 65 years and over
}

\author{
Richard H. T. Gannon ${ }^{1}$, D. Joe Millward ${ }^{1}$, Jonathan E. Brown ${ }^{1}$, Helen M. Macdonald ${ }^{2}$, David P. Lovell ${ }^{3}$,
} Lynda A. Frassetto ${ }^{4}$, Thomas Remer ${ }^{5}$ and Susan A. Lanham-New ${ }^{1}$

${ }^{1}$ Division of Nutrition, Dietetics and Food Sciences, Faculty of Health and Medical Sciences, University of Surrey, Guildford, Surrey GU2 7XH, UK

${ }^{2}$ Department of Medicine and Therapeutics, University of Aberdeen, Aberdeen AB25 2ZD, UK

${ }^{3}$ Postgraduate Medical School, University of Surrey, Guildford GU2 7WG, UK

${ }^{4}$ Department of Medicine and General Clinical Research Center, University of California, San Francisco, CA, USA

${ }^{5}$ Department of Nutrition and Health, Research Institute of Child Nutrition, Dortmund, Germany

(Received 3 January 2007 - Revised 15 November 2007 - Accepted 26 November 2007 - First published online 8 April 2008)

Dietary intake has been shown to influence acid-base balance in human subjects under tightly controlled conditions. However, the net effect of food groups on alkali/acid loading in population groups is unclear. The aims of the present study were to: (1) quantify estimates of daily net endogenous acid production (NEAP) (mEq/d) in a representative group of British elderly aged 65 years and older; (2) compare and characterise NEAP by specific nutrients and food groups likely to influence dietary acid loading; (3) determine whether geographical location influenced NEAP. The National Diet and Nutrition Survey dataset, consisting of a $4 \mathrm{~d}$ weighed record and anthropometric data, was used to estimate dietary acidity. Dietary under-reporters were excluded by analysing only subjects with energy intakes $\geq 1 \cdot 2 \times$ BMR. NEAP was estimated as the dietary potential renal acid load + organic acid excretion, the latter as a multiple of estimated body surface area. NEAP was lower in women compared with men $(P<0.001)$, and lower than values reported in a Swedish elderly cohort. Lower dietary acidity was significantly associated with higher consumption of fruit and potatoes and lower consumption of meat, bread and eggs $(P<0.02$ to $P<0.001)$. Lower intakes of fish and cheese were associated with lower NEAP in men only $(P<0.01$ to $P<0 \cdot 001)$. There were regional differences for NEAP, with higher intakes in Scotland/ Northern regions compared with Central/South-Western and London/South-Eastern regions $(P=0 \cdot 01)$. These data provide an insight into the acid-generating potential of the diet in the British elderly population, which may have important consequences in this vulnerable group.

Net endogenous acid production: Acid-base balance: Food groups: British elderly

Acid-base homeostasis is critical to health; examples of the negative health effects of increases in acid loading or acidosis include growth retardation of babies, decline in sports performance and increased atrophy and loss of muscle mass ${ }^{(1-4)}$. There is increasing evidence to suggest that even small disturbances in acid-base homeostasis have deleterious effects on bone remodelling in the animal/cellular model, and may be a risk factor for osteoporosis especially given that a high dietary acid load may have a negative effect on bone health by increasing $\mathrm{Ca}$ excretion and bone resorption ${ }^{(5-8)}$. In addition, dietary acid loading can have detrimental health outcomes through an increased urinary $\mathrm{N}$ loss and nephrolithiasis ${ }^{(9,10)}$. Currently, there is a general consensus that diet can undoubtedly affect acid-base balance and that an individual's net acid load can be specifically modified by dietary intervention ${ }^{(11-13)}$.
Renal net acid excretion can be measured directly with $24 \mathrm{~h}$ urine collection, but this is impractical in large population groups. A more practical indirect measurement of acid-base balance in healthy individuals has been developed that relies on predictions using validated formulae from nutrient intake data. However, several algorithms for estimating the daily net endogenous acid production (NEAP) from the dietary composition of foods have been proposed by different investigators ${ }^{(10)}$. One such validated measurement was developed by Remer et al. and estimates the dietary potential renal acid load (PRAL), together with an assumed urinary excretion rate of organic acids (OA) which is predicted from body surface area (BSA) ${ }^{(2)}$. Since Remer and Frassetto have demonstrated that diets rich in protein precursors cause an increase in acidity and, conversely, diets rich in $\mathrm{K}$ (organic anions) have an alkalising effect ${ }^{(10)}$, a simpler

Abbreviations: BSA, body surface area; IQR, interquartile range; NDNS, National Diet and Nutrition Survey; NEAP, net endogenous acid production; OA, organic acid; PRAL, potential renal acid load.

* Corresponding author: Mr Richard Gannon, fax +44 1483 686401, email r.gannon@surrey.ac.uk 
algorithm, based on the protein: $\mathrm{K}$ ratio, has been formulated by Frassetto et al. ${ }^{(11)}$.

The principal aims of the present analysis were to: (1) quantify estimates of NEAP in a national representative sample of British elderly men and women aged 65 years and older categorised by different age groups and between sexes; (2) compare and characterise NEAP in relation to food groups likely to influence dietary acid; (3) determine whether geographical location in the UK influenced estimates of NEAP.

\section{Methodology}

The National Diet and Nutrition Survey (NDNS) is an ongoing joint initiative established in 1990 by the UK Ministry of Agriculture, Fisheries and Food and the Department of Health. The aims of the NDNS are to provide a comprehensive cross-sectional representation of the dietary habits and nutritional status of the population of Great Britain. The survey provides quantitative data on food and nutrient intakes ( $4 \mathrm{~d}$ weighed diet record), anthropometric measurements, demographic and lifestyle characteristics and other related biochemical indices.

The present study focuses on the NDNS for individuals aged 65 years and over ${ }^{(14)}$, with analysis restricted to those who provided a full $4 \mathrm{~d}$ food diary. Of an eligible sample of 2172 participants, $1275(59 \%)$ free-living adults completed a food diary. Additionally, $412(91 \%)$ of participants in institutions (nursing homes and residential homes for the elderly excluding individuals in acute hospital beds) completed a diet diary. Under-reporters were excluded with an energy intake:BMR ratio of $<1 \cdot 2^{(15)}$, with BMR calculated using the equation based on the mean weight for the elderly population group as $13.5 W+487$ in men and $10 \cdot 5 W+596$ for women, where $W$ is the average weight in $\mathrm{kg}^{(16)}$. This meant that 740 participants remained, of which 449 were men and 291 were women. A further nineteen participants were excluded from the analysis as their anthropometric data were not recorded. The survey was conducted between October 1994 and September 1995 in four stages, approximately corresponding to the four seasons of the year ${ }^{(17)}$.

The NDNS dataset was downloaded from the UK Data Archive, University of Essex. A master data file was created using variables taken from different portable SPSS data files as provided by the principal investigators. Each food code for a particular food group was summed together to give a total value for that food type. Participants were classified into quartiles based on their age, and net dietary acid load using estimated NEAP.

Descriptions of the earlier and most recent calculation models for NEAP are described elsewhere ${ }^{(2,11,12)}$. In the past, investigators have used different algorithms for estimating the diet's daily net acid load, even when the estimates were derived essentially from the same input variables, and this had led to some terminological confusion. Because of this, investigators in the field have recently agreed on standardised terminology related to estimating the dietdependent net acid load from the composition of the diet, based on accepted physiological principles ${ }^{(10)}$. Throughout the present paper the term NEAP represents PRAL + OA or the protein: $\mathrm{K}$ algorithm where specified.

\section{Estimates of daily net acid load}

Dietary acid is produced by the metabolism of the amino acids cysteine and methionine from protein to sulfuric acid. Dietary bases are the weak OA salts of $\mathrm{Mg}, \mathrm{K}$ and $\mathrm{Ca}$, such as potassium citrate, which forms bicarbonate. The net balance between sulfate and phosphate, $\mathrm{Mg}, \mathrm{K}$ and $\mathrm{Ca}$ represents the PRAL. In addition OA are excreted representing the incomplete metabolism of fats and carbohydrates and some minor dietary sources. Thus, overall net dietary acid production (NEAP) reflects the value of PRAL from acid- and base-forming components ingested daily plus OA. For the body to remain in acid-base balance, the net amount of acid excreted should be equal to the net amount of acid produced. In contrast to the original PRAL equation $\mathrm{Na}$ and $\mathrm{Cl}$ are not included since they are usually balanced in the diet; however, Ca has been included as it is makes an important contribution to the overall dietary alkalinity in this elderly group.

Estimated NEAP $(\mathrm{mEq} / \mathrm{d})$ was calculated using the formula as detailed elsewhere ${ }^{(2,10)}$ :

$$
\sum\left(\left(\mathrm{SO}_{4}+\mathrm{P}+\text { endogenous } \mathrm{OA}\right)-(\mathrm{Mg}+\mathrm{K}+\mathrm{Ca})\right) .
$$

Where $\mathrm{SO}_{4}$ is sulfate calculated from the dietary protein $(\mathrm{g} /$ day $) \times 0.4888$; $\mathrm{P}$, phosphorus $(\mathrm{mg} /$ day $) \times 0.0366$; $\mathrm{K}$, potassium $(\mathrm{mg} /$ day $) \times 0.0205 ; \mathrm{Mg}$, magnesium, $\mathrm{mg} /$ day $\times 0.0263$; $\mathrm{Ca}$, calcium $(\mathrm{mg} /$ day $) \times 0.0125$.

This algorithm takes into account the average intestinal absorption rates of ingested protein and additional minerals as well as an anthropometry-based estimate for organic acid excretion.

Endogenous OA were calculated from the BSA of each subject using the formula ${ }^{(18)}$ :

$$
\text { Endogenous } \mathrm{OA}=41 \times \mathrm{BSA}\left(\mathrm{m}^{2}\right) / 1.73\left(\mathrm{~m}^{2}\right) .
$$

BSA was calculated using the following formula ${ }^{(19)}$ :

$$
\operatorname{BSA}\left(\mathrm{m}^{2}\right)=\operatorname{weight}(\mathrm{kg})^{0.425} \times \text { height }(\mathrm{cm})^{0.725} \times 0.00718 .
$$

A reasonable correlation of the above NEAP estimate with analysed net acid excretion in $24 \mathrm{~h}$ urine samples (the gold standard for assessing net endogenous acid load) has been demonstrated in healthy adults and more recently in children and 16-18-year-old adolescents ${ }^{(2,12)}$.

A simpler calculation of NEAP estimates dietary acid intake from protein intake (an acid precursor) and $\mathrm{K}$ (an index of base precursors from OA) using the formula ${ }^{(10,11)}$ :

$$
\begin{aligned}
\operatorname{EstimatedNEAP}(\mathrm{mEq} / \mathrm{d}) & =(54 \cdot 5 \times \operatorname{protein}(\mathrm{g} / \mathrm{d}) / \mathrm{K}(\mathrm{mEq} / \mathrm{d})) \\
& -10 \cdot 2 .
\end{aligned}
$$

\section{Classification of food groups}

Table 1 presents the individual food items in each of the food groups most commonly consumed by all participants.

\section{Statistical analysis}

Statistical analyses were performed using SPSS software (version 13, 2005; SPSS Inc., Chicago, IL, USA). Descriptive statistics (median and interquartile range; IQR) were determined for all variables. Data were checked for normality 
Table 1. Classification of food groups

\begin{tabular}{|c|c|}
\hline $\begin{array}{l}\text { Grouped food }(\mathrm{g}) / \\
\text { drink }(\mathrm{ml})\end{array}$ & Description of food/drink consumed \\
\hline Fruits & $\begin{array}{l}\text { Fresh fruit; apples and pears, citrus fruit and } \\
\text { bananas, other fruits; frozen and canned fruit }\end{array}$ \\
\hline Vegetables & $\begin{array}{l}\text { Fresh vegetables, carrots, tomatoes, leafy green } \\
\text { vegetables (including broccoli), salads and } \\
\text { vegetable dishes/other vegetables, frozen } \\
\text { and canned vegetables }\end{array}$ \\
\hline Legumes & Peas, green beans and baked beans \\
\hline Meats & $\begin{array}{l}\text { Bacon and ham, beef, veal, lamb, pork, chicken } \\
\text { and turkey, liver, other meat dishes/meat } \\
\text { products (including canned meat) }\end{array}$ \\
\hline Fish & $\begin{array}{l}\text { White and oily fish, shellfish, other fish } \\
\text { dishes/fish products (including canned fish) }\end{array}$ \\
\hline Potatoes & $\begin{array}{l}\text { Boiled, mashed and fried/roasted, potato salads } \\
\text { and dishes }\end{array}$ \\
\hline Bread & $\begin{array}{l}\text { White and wholemeal bread, softgrain, rolls and } \\
\text { other bread products }\end{array}$ \\
\hline Cereals & $\begin{array}{l}\text { Pasta and rice, breakfast cereals and other } \\
\text { cereals }\end{array}$ \\
\hline Biscuits/cakes & $\begin{array}{l}\text { Biscuits (sweet and savoury), fruit pies, buns, } \\
\text { cakes and pastries }\end{array}$ \\
\hline Milk/yoghurts & $\begin{array}{l}\text { Whole, semi-skimmed, skimmed and other } \\
\text { milk and yoghurt (including goats', sheep } \\
\text { and soya) and fromage frais }\end{array}$ \\
\hline Cheeses & $\begin{array}{l}\text { Cottage cheese and other cheese (soft cream, } \\
\text { hard, vegetarian and processed) }\end{array}$ \\
\hline Eggs & Eggs and egg dishes \\
\hline Desserts & $\begin{array}{l}\text { Cereal-based milk puddings (dairy), } \\
\text { sponge-type puddings, other puddings } \\
\text { and ice-cream }\end{array}$ \\
\hline Preserves & $\begin{array}{l}\text { Jams, fruit spread, marmalade, honey and } \\
\text { lemon curd }\end{array}$ \\
\hline Coffee & Instant, coffee bean and decaffeinated \\
\hline Tea/herbal teas & Infusion, instant and decaffeinated \\
\hline Water & $\begin{array}{l}\text { Tap water, bottled water, still or carbonated, } \\
\text { but not sweetened waters }\end{array}$ \\
\hline Savoury/sauces & $\begin{array}{l}\text { White sauces, sauce mixes, tomato ketchup, } \\
\text { gravy, mayonnaise }\end{array}$ \\
\hline
\end{tabular}

using the Kolmogorov-Smirnov test. Variables that were normally distributed were analysed using ANOVA with the Tukey post hoc test. Variables that were not normally distributed were analysed using the Kruskal-Wallis non-parametric test. An independent two-sample $t$ test was used to determine differences between sexes.

In order to determine differences between quartiles of NEAP values the Kruskal-Wallis test was used. The Mann-Whitney $U$ test was used to identify which specific quartiles were different from one another due to the lack of a non-parametric post hoc test for SPSS. A Bonferroni correction was applied to take into account multiple testing. Spearman correlation coefficients were calculated for variables that were nonnormally distributed. For comparisons of dietary acidity between regions, ANOVA with Tukey post hoc tests were used.

\section{Results}

Nutrient and anthropometric measurements in net endogenous acid production dataset

Tables 2 and 3 show the anthropometric and nutrient characteristics of the elderly males and females respectively. Median daily intake for energy was below the UK estimated
Table 2. Anthropometric measurements in men and women† (Median values and interquartile ranges (IQR))

\begin{tabular}{|c|c|c|c|c|}
\hline \multirow[b]{2}{*}{ Factor } & \multicolumn{2}{|c|}{ Men ( $n$ 437) } & \multicolumn{2}{|c|}{ Women ( $n$ 284) } \\
\hline & Median & IQR & Median & IQR \\
\hline Age & 76 & 11 & 80 & 14 \\
\hline BMI $\left(\mathrm{kg} / \mathrm{m}^{2}\right)$ & $25 \cdot 5$ & $5 \cdot 1$ & $24 \cdot 4$ & 5.9 \\
\hline Energy intake:BMR & 1.43 & 0.3 & $1.4^{*}$ & 0.3 \\
\hline Weight (kg) & $71 \cdot 3$ & $16 \cdot 5$ & $58 \cdot 0^{\star \star \star}$ & $14 \cdot 8$ \\
\hline Height (cm) & $167 \cdot 8$ & $10 \cdot 5$ & $153 \cdot 9^{\star \star \star}$ & $10 \cdot 5$ \\
\hline
\end{tabular}

Median value was significantly different from that for men: ${ }^{\star} P<0.05,{ }^{\star \star \star} P<0.001$ †An independent two-sample $t$ test was used for the analysis. Tests are between men and women.

average requirement. However, daily intakes for protein, $\mathrm{Ca}$, $\mathrm{P}$ and vitamin $\mathrm{C}$ were higher than the reference nutrient intake in elderly males and females ${ }^{(20)}$. Median daily intakes of $\mathrm{K}$ and $\mathrm{Mg}$ were below the reference nutrient intake in elderly men and women respectively. Women had significantly lower values $(P<0 \cdot 001)$ for each of the macro- and micronutrients, except for vitamin $\mathrm{C}(P<0.05)$ and on average were older and had a slightly lower BMI.

Estimates of dietary acidity in the UK population: age and sex specific

Estimates of dietary acidity in the UK elderly population using NEAP categorised according to sex and different age groups are summarised in Table 4 . The median value for NEAP was $15.5 \%$ higher in men than women $(P<0.001)$. There were no significant changes according to age banding in either men or women.

\section{Dietary nutrient profile according to quartiles of dietary acidity}

A comparison of the median values for the macro- and micronutrients categorised according to quartiles of acidity is shown in Table 5. For estimates of NEAP in men and women higher energy, protein, fat and $\mathrm{P}$ intakes were significantly associated with higher acid loads $(P<0 \cdot 001)$. Higher $\mathrm{Ca}$ intakes were significantly associated with higher acid

Table 3. Macro- and micronutrient intake for men and woment (Median values and interquartile ranges (IQR))

\begin{tabular}{|c|c|c|c|c|}
\hline \multirow[b]{2}{*}{ Nutrient } & \multicolumn{2}{|c|}{ Men ( $n$ 449) } & \multicolumn{2}{|c|}{ Women (n 291) } \\
\hline & Median & IQR & Median & IQR \\
\hline Energy (kJ) & 8757 & 1891 & $7054^{\star \star \star}$ & 1389 \\
\hline Energy (kcal) & 2093 & 452 & $1686^{\star \star *}$ & 332 \\
\hline Protein (g) & 74 & 20 & $60^{\star \star \star}$ & 18 \\
\hline Carbohydrate (g) & 263 & 70 & $212^{\star \star *}$ & 56 \\
\hline Fat $(\mathrm{g})$ & 83 & 26 & $71^{\star \star \star}$ & 21 \\
\hline $\mathrm{Ca}(\mathrm{mg})$ & 922 & 334 & $839^{\star \star *}$ & 318 \\
\hline $\mathrm{K}(\mathrm{mg})$ & 2848 & 941 & $2317^{\star \star \star}$ & 818 \\
\hline $\mathrm{Mg}(\mathrm{mg})$ & 266 & 108 & $212^{\star \star \star}$ & 82 \\
\hline$P(\mathrm{mg})$ & 1321 & 387 & $1091^{\star \star *}$ & 368 \\
\hline Vitamin C (mg) & 60 & 48 & $47^{\star}$ & 45 \\
\hline
\end{tabular}

Median value was significantly different from that for men: ${ }^{*} P<0.05$ ${ }^{\star * \star} P<0.001$.

†An independent two-sample $t$ test was used for the analysis. Tests are between men and women. 
Table 4. Comparison of net endogenous acid production (NEAP) between sex and across the different age groups

(Median values and interquartile ranges (IQR))

\begin{tabular}{|c|c|c|c|c|c|c|c|c|c|c|c|c|c|c|c|c|c|c|c|c|c|c|}
\hline \multirow{3}{*}{$\begin{array}{l}\text { Sex... } \\
\text { Age } \\
\text { group } \\
\text { (years)... }\end{array}$} & \multicolumn{11}{|c|}{ Men } & \multicolumn{11}{|c|}{ Women } \\
\hline & \multicolumn{3}{|c|}{ All } & \multicolumn{2}{|c|}{$65-71(n 136)$} & \multicolumn{2}{|c|}{$72-77(n-124)$} & \multicolumn{2}{|c|}{$78-84(n 101)$} & \multicolumn{2}{|c|}{$85-100(n 76)$} & \multicolumn{3}{|c|}{ All } & \multicolumn{2}{|c|}{$65-71(n 72)$} & \multicolumn{2}{|c|}{$72-79(n 72)$} & \multicolumn{2}{|c|}{$80-86(n 70)$} & \multicolumn{2}{|c|}{$87-101(n$ 70) } \\
\hline & Median & IQR & Range & Median & IQR & Median & IQR & Median & IQR & Median & IQR & Median & IQR & Range & Median & IQR & Median & IQR & Median & IQR & Median & IQR \\
\hline NEAP $\ddagger$ & 50.5 & 14.0 & $18.0-84.9$ & 51.0 & $13 \cdot 0$ & 50.0 & 15.5 & 50.5 & 15.5 & 49.9 & $12 \cdot 7$ & $42 \cdot 7^{\star \star \star}$ & 11.7 & $13 \cdot 0-68 \cdot 7$ & 41.2 & $12 \cdot 3$ & 44.1 & 11.0 & 43.5 & 11.4 & 41.9 & 11.6 \\
\hline
\end{tabular}

${ }^{* * *}$ Median value was significantly different from that for men $(P<0.001)$.

AANOVA and Tukey post hoc tests were used for the analyses. An independent two-sample $t$ test was used for the analysis. Tests are between men and women

ANOVA

Table 5. Comparison of net endogenous acid production (NEAP) by quartile and daily intake of macro- and micronutrients $\dagger$

(Median values and interquartile ranges (IQR))

\begin{tabular}{|c|c|c|c|c|c|c|c|c|c|c|c|c|c|c|c|c|}
\hline \multirow{2}{*}{$\begin{array}{l}\text { Sex... } \\
\text { Quartiles of NEAP } \ddagger . .\end{array}$} & \multicolumn{8}{|c|}{ Men $(n 437)$} & \multicolumn{8}{|c|}{ Women (n 284) } \\
\hline & \multicolumn{2}{|c|}{1} & \multicolumn{2}{|c|}{2} & \multicolumn{2}{|c|}{3} & \multicolumn{2}{|c|}{4} & \multicolumn{2}{|c|}{1} & \multicolumn{2}{|c|}{2} & \multicolumn{2}{|c|}{3} & \multicolumn{2}{|c|}{4} \\
\hline NEAP (mEq/d) & \multicolumn{2}{|c|}{$39.4(n$ 109) } & \multicolumn{2}{|c|}{$47.6(n$ 109) } & \multicolumn{2}{|c|}{$54.0(n$ 110) } & \multicolumn{2}{|c|}{$62.7(n$ 109) } & \multicolumn{2}{|c|}{$33.5(n 71)$} & \multicolumn{2}{|c|}{$40.5(n 71)$} & \multicolumn{2}{|c|}{$46 \cdot 1(n 71)$} & \multicolumn{2}{|c|}{$53.4(n 71)$} \\
\hline Daily intake & Median & IQR & Median & IQR & Median & IQR & Median & IQR & Median & IQR & Median & IQR & Median & IQR & Median & IQR \\
\hline Energy (kJ) & $8230^{a, c}$ & 1820 & $8895^{c, d}$ & 1715 & $8858^{\mathrm{c}, \mathrm{d}}$ & 1707 & $9129^{b, d}$ & 2084 & $6766^{\mathrm{a}, \mathrm{c}}$ & 1130 & $6820^{a}$ & 1151 & $7410^{d}$ & 1443 & $7573^{b}$ & 1695 \\
\hline Energy (kcal) & $1967^{\mathrm{a}, \mathrm{c}}$ & 435 & $2126^{c, d}$ & 410 & $2117^{\mathrm{c}, \mathrm{d}}$ & 408 & $2182^{b, d}$ & 498 & $1617^{\mathrm{a}, \mathrm{c}}$ & 270 & $1630^{a}$ & 275 & $1771^{d}$ & 345 & $1810^{\mathrm{b}}$ & 405 \\
\hline Protein $(\mathrm{g}) \S$ & $66^{\mathrm{a}}$ & 18 & $72^{\mathrm{a}, \mathrm{b}, \mathrm{e}}$ & 20 & $77^{\mathrm{a}, \mathrm{b}, \mathrm{f}}$ & 15 & $85^{\mathrm{b}}$ & 24 & $53^{\mathrm{a}}$ & 14 & $58^{\mathrm{a}, \mathrm{c}}$ & 14 & $62^{a, b, d}$ & 14 & $72^{b}$ & 17 \\
\hline Carbohydrate (g) & 265 & 59 & 264 & 75 & 257 & 64 & 262 & 74 & 215 & 46 & 212 & 48 & 211 & 58 & 215 & 69 \\
\hline Fat $(\mathrm{g})$ & $74^{\mathrm{a}, \mathrm{c}}$ & 26 & $81^{\mathrm{a}, \mathrm{d}}$ & 23 & $83^{e, b}$ & 26 & $91^{\mathrm{b}, \mathrm{f}}$ & 22 & $64^{a, c}$ & 16 & $68^{a, d}$ & 19 & $75^{\mathrm{b}}$ & 18 & $78^{\mathrm{b}}$ & 20 \\
\hline $\mathrm{Ca}(\mathrm{mg}) \S$ & $833^{\mathrm{a}, \mathrm{c}, \mathrm{e}}$ & 267 & $932^{d}$ & 341 & $900^{f}$ & 329 & $965^{b}$ & 380 & 815 & 297 & 816 & 398 & 866 & 335 & 843 & 354 \\
\hline $\mathrm{K}(\mathrm{mg}) \S$ & $3085^{\mathrm{e}}$ & 854 & 2868 & 1020 & $2781^{\dagger}$ & 799 & 2771 & 841 & 2426 & 1060 & 2265 & 736 & 2233 & 650 & 2384 & 719 \\
\hline $\mathrm{Mg}(\mathrm{mg}) \S$ & 277 & 117 & 260 & 121 & 268 & 95 & 265 & 97 & 207 & 100 & 206 & 76 & 209 & 81 & 222 & 87 \\
\hline$P(m g) \S$ & $1198^{\mathrm{a}, \mathrm{c}}$ & 369 & $1315^{\mathrm{c}, \mathrm{d}}$ & 455 & $1320^{\mathrm{d}, \mathrm{e}}$ & 344 & $1420^{b, d, f}$ & 447 & $981^{a}$ & 336 & $1037^{\mathrm{a}}$ & 336 & $1104^{c}$ & 307 & $1184^{b, d}$ & 386 \\
\hline Vitamin C (mg) & $72^{\mathrm{c}}$ & 59 & $62^{\mathrm{e}}$ & 49 & 58 & 34 & $51^{\mathrm{d}, \mathrm{f}}$ & 41 & $66^{c}$ & 85 & 49 & 41 & $43^{d}$ & 34 & $43^{d}$ & 33 \\
\hline
\end{tabular}

Values with unlike superscript letters between quartiles and within sex were significantly different as follows: ${ }^{a, b} P<0.001,{ }^{c, d} P<0.01,{ }^{e, f} P<0.02$

† Kruskal-Wallis and Mann-Whitney tests were used for the analysis. Tests are between men and women.

FNEAP $=$ potential renal acid load $(\mathrm{mEq} / \mathrm{d})+$ estimated urinary organic anions $(\mathrm{mEq} / \mathrm{d})^{(2,10)}$

\& Nutrients included in NEAP estimation. 
loads in men $(P<0.001)$ but not women. Lower $\mathrm{K}$ levels were associated with a higher dietary acid load in men $(P<0 \cdot 02)$. Although there was a non-significant trend for intakes of $\mathrm{Mg}$ to fall with increasing dietary acidity in men, the opposite was observed in women, with lower levels of $\mathrm{Mg}$ associated with lower dietary acid loads. There was a clear reduction in vitamin $\mathrm{C}$ levels with increasing dietary acidity for both men and women $(P<0.01$ respectively).

\section{Dietary food group profile according to quartiles of dietary} acidity

A comparison of the median values for food groups categorised according to quartiles of NEAP is shown in Table 6. An increase in NEAP was significantly associated with a reduction in fruit intakes in elderly men $(P<0 \cdot 01)$ and women $(P<0.02)$ respectively. There was a trend for vegetable consumption to fall in men with increasing NEAP but this was not significant. There was no clear or significant trend for changes in legume consumption in men or women with increasing NEAP. Higher intakes of meat and eggs significantly contributed to higher NEAP in men $(P<0.001$; $P<0.001)$ and women $(P<0.001 ; P<0.02)$ respectively. For fish, higher intakes significantly contributed to higher NEAP in men $(P<0.01)$, and a similar but non-significant trend was observed in women. Higher potato intakes in elderly males and females were significantly associated with lower NEAP values $(P<0 \cdot 01)$. Lower consumption of bread was associated with lower NEAP in both elderly males $(P<0.001)$ and females $(P<0.02)$ respectively. There was no clear or significant trend for changes in cereal consumption with an increase in NEAP in men or women. Milk and yoghurt intakes varied widely with no significant trend according to NEAP intakes. Higher intakes of cheese in men were associated with increased NEAP values $(P<0.001)$, and a marginal non-significant increase was also observed in women There was a significant association between increased consumption of biscuits and cakes and higher estimates of NEAP in women $(P<0.02)$. Increased consumption of desserts was significantly associated with higher NEAP values in women $(P<0.01)$. Higher intakes of preserves and jams were significantly associated with increased NEAP between quartiles 1 and 3 and 2 and $3(P<0.02)$ in men, but there was no relationship with NEAP values in women. Coffee consumption in women significantly fell with increasing NEAP $(P<0 \cdot 01)$, but there was no clear trend in men. Higher tea consumption was significantly associated with lower NEAP values between the latter two quartiles in elderly women $(P<0 \cdot 001)$. The opposite was seen in men, with higher intakes having a positive impact on dietary acid load. Increased consumption of water in men and women was associated with a reduction in NEAP. Consumption of savoury and sauces in women varied widely, with a trend towards higher intakes being associated with increased estimates of NEAP; however, there was no clear trend in men.

\section{Estimates of dietary acidity according to geographical} location

Fig. 1 represents the median dietary acid loadings for the different UK regions. NEAP was highest in Scotland and
Northern England, respectively, and lowest for participants living in London and South-Eastern England, with intermediate values in Central and South-Western England, with the North-South differences significant $(P=0 \cdot 01)$.

\section{Correlation between estimates of net endogenous acid} production using dietary potential renal acid load + organic acid and protein:potassium algorithm

Fig. 2 shows the correlation between PRAL + OA and protein: $\mathrm{K}$ algorithm. There is a significant association between the two algorithms which explained $54 \%$ of the variance ( $r 0.72 ; P<0.001$ ). However, at higher values of NEAP the relationship is more variable. Thus within the top quartile of NEAP, variations in PRAL + OA explain only $18 \%$ of the variation in protein: $\mathrm{K}$ algorithm compared with $38 \%$ in the bottom quartile.

The main reason for the deviation between the two estimates of NEAP is the OA term which closely reflects the fact that OA anion excretion is not primarily diet-dependent, but based on the PRAL + OA model which is mainly determined by body size ${ }^{(21)}$.

\section{Discussion}

The principal objective of the present study was to investigate the dietary acid burden in the UK elderly population from food intakes as measured by a $4 \mathrm{~d}$ food diary and reported as the NDNS of British adults aged 65 years and over. A second objective was to compare and characterise NEAP by specific nutrients and food groups likely to influence dietary acid loading; the third objective was to determine whether geographical location influences estimates of NEAP. In the present paper for the first time we demonstrate regional differences in NEAP, i.e. higher values in Northern regions compared with Southern. NEAP was also lower in women compared with men, and those eating more fruit and potatoes and less meat, fish, eggs, cheese and bread.

A number of algorithms have been developed for estimating NEAP from food composition tables. However, it was felt that for this present study the equation PRAL + OA was a more robust method to determine the diet-dependent daily net acid load. One potential weakness of the algorithm NEAP is the assumption that OA production is a fixed function of body size (endogenous $\mathrm{OA}=41 \times \mathrm{BSA}$ ). In fact $\mathrm{OA}$ is difficult to measure completely and multiple methods for estimating OA excretion have been used ${ }^{(18)}$. Furthermore, increasing dietary alkali load (for example, by increasing the intake of fruits and vegetables) has been reported to increase OA production to a greater extent than acid excretion ${ }^{(22)}$. However, the prediction equation has been demonstrated in children and 16-18-year-old adolescents, and in healthy adults consuming diets containing variable amounts of protein where measured OA excretion rates were very similar to the predicted value ${ }^{(2,12)}$. It is generally accepted that the influence of dietary acidity or alkalinity on NEAP is, in principle, additive or subtractive to the amounts of acid equivalents derived from the (body size-dependent) metabolic system. Correspondingly, it appears predictable that both NEAP estimates (the sum estimate and the ratio estimate) deviate more noticeably from each other when changes in dietary acid load 
Table 6. Consumption of food groups according to quartiles of net endogenous acid production (NEAP) $\dagger$ (Median values and interquartile ranges (IQR))

\begin{tabular}{|c|c|c|c|c|c|c|c|c|c|c|c|c|c|c|c|c|}
\hline \multirow{3}{*}{$\begin{array}{l}\text { Sex... } \\
\text { Quartiles of NEAP } \neq . . \\
\text { Daily intake }(\mathrm{g})\end{array}$} & \multicolumn{8}{|c|}{ Men ( $n$ 437) } & \multicolumn{8}{|c|}{ Women ( $n$ 284) } \\
\hline & \multicolumn{2}{|c|}{1} & \multicolumn{2}{|c|}{2} & \multicolumn{2}{|c|}{3} & \multicolumn{2}{|c|}{4} & \multicolumn{2}{|c|}{1} & \multicolumn{2}{|c|}{2} & \multicolumn{2}{|c|}{3} & \multicolumn{2}{|c|}{4} \\
\hline & Median & IQR & Median & IQR & Median & IQR & Median & IQR & Median & IQR & Median & IQR & Median & IQR & Median & IQR \\
\hline Subjects $(n)$ & \multicolumn{2}{|c|}{109} & \multicolumn{2}{|c|}{109} & \multicolumn{2}{|c|}{110} & \multicolumn{2}{|c|}{109} & \multicolumn{2}{|c|}{71} & \multicolumn{2}{|c|}{71} & \multicolumn{2}{|c|}{71} & \multicolumn{2}{|c|}{71} \\
\hline Fruit & $190^{c}$ & 268 & 158 & 207 & $115^{\mathrm{d}}$ & 199 & $94^{d}$ & 204 & $152^{e}$ & 248 & $139^{a}$ & 151 & $60^{\mathrm{b}}$ & 95 & $109^{f}$ & 141 \\
\hline Vegetables & 168 & 167 & 152 & 138 & 136 & 139 & 133 & 155 & 148 & 131 & 105 & 88 & 116 & 101 & 124 & 145 \\
\hline Legumes & 32 & 71 & 46 & 64 & 36 & 66 & 29 & 80 & 26 & 53 & 26 & 53 & 28 & 37 & 27 & 56 \\
\hline Meats & $159^{a, c}$ & 143 & $208^{\mathrm{c}, \mathrm{d}}$ & 121 & $219^{\mathrm{b}}$ & 119 & $249^{\mathrm{b}, \mathrm{d}}$ & 187 & $116^{\mathrm{a}}$ & 107 & $137^{\mathrm{a}, \mathrm{c}}$ & 94 & $175^{\mathrm{b}, \mathrm{d}}$ & 103 & $214^{\mathrm{b}}$ & 104 \\
\hline Fish & $44^{c}$ & 84 & 49 & 77 & 50 & 65 & $76^{\mathrm{d}}$ & 103 & 44 & 52 & 42 & 68 & 48 & 79 & 53 & 81 \\
\hline Potatoes & $215^{\mathrm{c}}$ & 179 & $201^{\mathrm{e}}$ & 148 & 206 & 130 & $168^{\mathrm{d}, \mathrm{f}}$ & 129 & $177^{\mathrm{c}}$ & 133 & 148 & 95 & 147 & 110 & $140^{\mathrm{d}}$ & 98 \\
\hline Bread & $176^{\mathrm{a}}$ & 122 & $178^{\mathrm{a}}$ & 98 & 189 & 94 & $222^{\mathrm{b}}$ & 121 & $135^{\mathrm{e}}$ & 70 & 144 & 77 & $165^{\mathrm{d}}$ & 68 & $171^{f}$ & 92 \\
\hline Cereals & 80 & 137 & 95 & 140 & 103 & 181 & 93 & 181 & 45 & 81 & 46 & 88 & 41 & 79 & 50 & 89 \\
\hline Biscuits/cakes & 104 & 112 & 130 & 124 & 109 & 90 & 118 & 110 & $84^{\mathrm{e}}$ & 78 & 102 & 84 & 102 & 84 & $115^{f}$ & 96 \\
\hline Milk/yoghurt & 432 & 311 & 517 & 371 & 435 & 273 & 485 & 360 & 449 & 297 & 462 & 432 & 494 & 417 & 483 & 360 \\
\hline Cheeses & $12^{\mathrm{a}}$ & 26 & $11^{\mathrm{a}, \mathrm{e}}$ & 26 & $18^{e, f}$ & 33 & $28^{\mathrm{b}, \mathrm{f}}$ & 59 & 12 & 28 & 11 & 28 & 9 & 25 & 18 & 34 \\
\hline Eggs & $20^{\mathrm{a}}$ & 31 & $22^{\mathrm{c}}$ & 50 & 26 & 59 & $44^{b}$ & 76 & $0.1^{\mathrm{e}}$ & 25 & 5 & 25 & 22 & 44 & $25^{f}$ & 53 \\
\hline Desserts & 70 & 158 & 93 & 191 & 118 & 152 & 88 & 178 & $74^{\mathrm{c}}$ & 154 & 92 & 166 & $138^{\mathrm{d}}$ & 180 & 99 & 188 \\
\hline Preserves/jams & $9^{e}$ & 26 & $12^{\mathrm{e}}$ & 27 & $19^{f}$ & 41 & 11 & 32 & 12 & 28 & 13 & 28 & 13 & 28 & 11 & 34 \\
\hline Coffee & 128 & 477 & 106 & 458 & 137 & 394 & 84 & 330 & $161^{\mathrm{C}}$ & 346 & $129^{c}$ & 381 & $0.1^{d}$ & 221 & 70 & 257 \\
\hline Tea/herbal tea & 1181 & 911 & 1208 & 950 & 1232 & 736 & 1267 & 707 & 1115 & 623 & 1093 & 628 & $1222^{a}$ & 674 & $1021^{\mathrm{b}}$ & 668 \\
\hline Water (ml) & 454 & 783 & 358 & 845 & 342 & 703 & 325 & 669 & 492 & 700 & 378 & 546 & 319 & 544 & 298 & 483 \\
\hline Savoury/sauces & 36 & 57 & 34 & 58 & 37 & 61 & 31 & 48 & 55 & 117 & 39 & 95 & 86 & 127 & 73 & 130 \\
\hline
\end{tabular}

Values with unlike superscript letters between quartiles and within sex were significantly different as follows: ${ }^{a, b} P<0.001,{ }^{c, d} P<0.01,{ }^{e, f} P<0.02$.

† Kruskal-Wallis and Mann-Whitney tests were used for the analysis.
†NEAP $=$ potential renal acid load $(\mathrm{mEq} / \mathrm{d})+$ estimated urinary organic anions $(\mathrm{mEq} / \mathrm{d})^{(2,10)}$. 


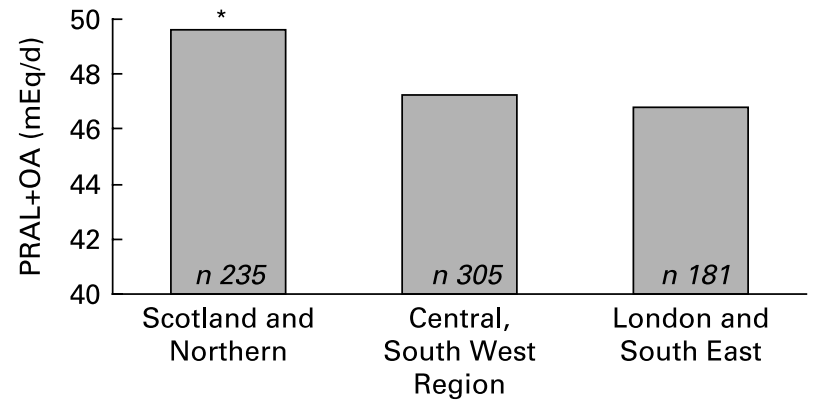

Fig. 1. Differences in median net endogenous acid production (NEAP) according to geographical location. NEAP = potential renal acid load (PRAL) $(\mathrm{mEq} / \mathrm{d})+$ estimated urinary organic anions $(\mathrm{OA})(\mathrm{mEq} / \mathrm{d})^{(2,10)}$. ANOVA and Tukey post hoc tests were used for the analysis. * Median value was significantly different from that for London and the South-East $(P=0.01)$.

increase overall NEAP. In this context it should be kept in mind that in diets typical of the UK and other industrialised countries, despite a low variance in analysed OA excretion, i.e. despite a relatively constant and high OA component (varying about $40 \mathrm{mEq} / \mathrm{d}$ on average), both analysed and estimated net acid excretion can vary considerably, only due to a change in the diet ${ }^{(12)}$. However, whatever estimate is used, true NEAP can only be determined in a metabolic setting where urinary losses of OA and faecal losses of organic anions can be measured ${ }^{(23)}$.

The assumption inherent in the present calculations is that urinary acid excretion balances the dietary and endogenous acid load so that the organism is in neutral acid-base balance. However, at high dietary acid loads this may not be the case, since previous studies have shown that with values greater than an average acid intake of approximately $1 \mathrm{mEq} / \mathrm{kg}$ body weight, net acid production is greater than net acid excretion, leading to positive acid balance ${ }^{(24)}$. Average calculated values for NEAP in the present studies were below this value, although a positive acid balance may have occurred in subjects at the upper end of the overall range of NEAP values.

The median value for NEAP in this present study was 47.9 (IQR 10.7 ) $\mathrm{mEq} / \mathrm{d}$ and is slightly lower than in a recent

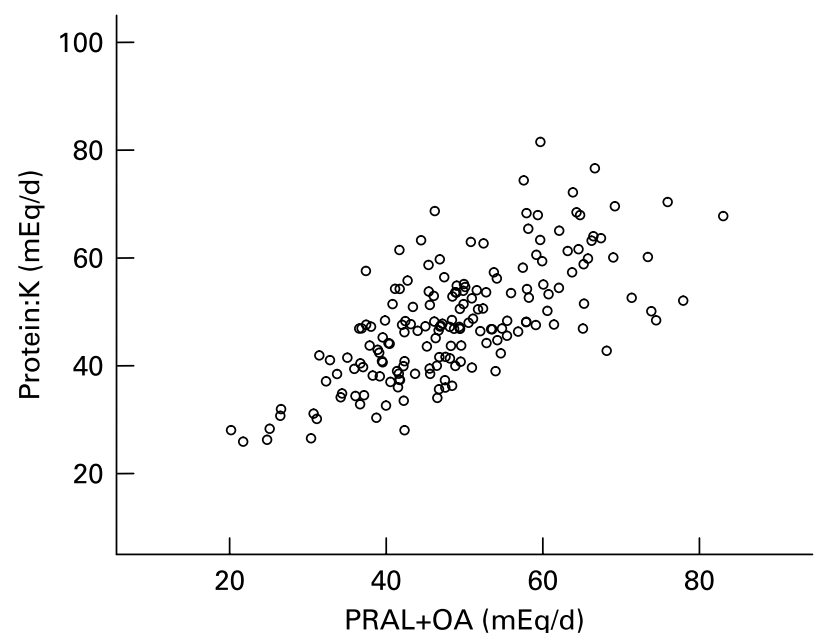

Fig. 2. Spearman's correlation of association $(r 0.72 ; P<0.01)$ using potential renal acid load + estimated urinary organic anions (PRAL + OA) and protein:K algorithm as estimates of net endogenous acid production. study of measured urinary acid excretion in a population of 400 elderly subjects (aged 55-75 years) with a mean of $60 \cdot 0(\mathrm{SD} 27 \cdot 0) \mathrm{mEq} / \mathrm{d}^{(25)}$, a value similar to previous reported measurements ${ }^{(12)}$. Since this was a more northerly (Swedish) population of elderly, it may be that the higher acidity reflected the same differences in dietary patterns which account for our finding of the higher acid diets for Scotland and Northern England compared with London and SouthernEastern England $(P=0 \cdot 01)$. A similar finding was found by Frassetto et al. where they showed that Sweden had the lowest intake of vegetable to animal protein ${ }^{(26)}$. It is the case that a lower intake of fruit and vegetables and a higher consumption of beef and veal (and dishes made from them) for Scotland and Northern England compared with the South have been reported. Moreover, participants in London and the South East were more likely to consume leafy green vegetables, semi-skimmed milk and coffee than in Scotland and Northern England ${ }^{(14)}$. However, the values here are also somewhat lower than those reported for Cambridge teenagers by Prynne et al. $(67.8 \mathrm{mEq} / \mathrm{d}$ for boys $v .53 .8 \mathrm{mEq} / \mathrm{d}$ for girls), although different dietary patterns are likely between teenagers and the elderly ${ }^{(27)}$. Interestingly, Lemann has estimated that the average diet consumed by American healthy adults generates approximately $50 \mathrm{mEq} / \mathrm{d}$, a value very similar to our findings ${ }^{(28)}$. Another plausible reason for the lower values is that the basic mineral $\mathrm{Ca}$ has not been excluded from the NEAP equation (see original equation) ${ }^{(2)}$. Removing $\mathrm{Ca}$ from the formula would result in a somewhat higher NEAP value $(59 \cdot 3$ (IQR 9.8) $\mathrm{mEq} / \mathrm{d})$ in this population group $^{(13)}$.

One potential problem in interpreting the original dataset is under-reporting. This is a major problem with the use of self-reporting dietary diaries, where under-reporting of true habitual food intake, as well as changing the diet during the survey, is a frequent problem ${ }^{(29)}$. Thus initial energy intakes (including all participants who completed a $4 \mathrm{~d}$ diary) were on average 1.24 (SD 0.32$) \times$ estimated BMR (7878 (SD 1958) kJ (1883 (SD 468) kcal) for men and 6109 (SD 1523) kJ (1460 (SD 364) kcal) for women respectively). This implies extensive under-reporting, and in fact $24 \%$ of the overall sample size had energy intakes $<1 \times$ BMR (19\% for men, $28 \%$ for women). Here we selected subjects on the basis of an energy intake:BMR ratio $\geq 1 \cdot 2$, resulting in mean energy intakes for the sub-sample of 1.47 (SD 0.23$) \times$ estimated BMR (8958 (SD 1565) kJ (2141 (SD 374) kcal) for men and 7305 (SD 1138) kJ (1746 (SD 272) kcal) for women respectively) ${ }^{(15,29)}$. In fact there was very little difference between NEAP for the complete sample compared with the trimmed sub-sample (47.1 (IQR 10.4) v. 47.9 (IQR 10.7) $\mathrm{mEq} / \mathrm{d}$ ).

The relationships between NEAP and macro- and micronutrients were to some extent but not entirely expected, demonstrating the importance of examining how these nutrients impact on dietary acid loading. Thus increasing NEAP was associated with increasing protein and $\mathrm{P}(P<0 \cdot 001)$ in elderly men and women, but somewhat surprisingly not with a significant fall in $\mathrm{K}$ (in women), $\mathrm{Mg}$ or $\mathrm{Ca}$, the latter actually significantly increasing in men. The increasing NEAP with increasing energy intakes is also likely to reflect the positive correlations between energy intakes and the other constituents listed in Table 5. Also the OA component of the algorithm, which is a major contributor to overall acidity, 
is predicted from body size and in this dataset varies positively with energy intake, albeit to a much lesser extent than protein or P. Of most interest as far as the single nutrients are concerned is the clear inverse relationship between NEAP and vitamin $\mathrm{C}$ in men and women $(P<0.01)$ and this has obvious implications in relation to the food groupNEAP relationships discussed below.

For food groups their expected relationships between increasing acidity was clear for intakes of the major dietary protein sources in terms of meat, fish, and eggs in both men and women. Conversely, higher intakes of potatoes had a significantly positive impact on dietary alkalinity in men and women $(P<0 \cdot 01)$, as potatoes were one of the largest individual consumed food item and have a rich $\mathrm{K}$ content. The importance of the association of fruit, which have a clear association with $\mathrm{K}$, with lower dietary acidity is emphasised here, as previously reported by others ${ }^{(13,27,30,31)}$. The combination of fruit and potatoes as alkalising components of the diet no doubt explains the clear relationship between vitamin $\mathrm{C}$ and a lower dietary acidity. For vegetables, however, intakes were independent of acidity; this may be due to the food grouping, as once the protein-rich vegetables (lentils, dried beans and pulses) were removed from the analysis the difference was almost significant $(P=0.06)$ between higher intakes and lower dietary acid load. Legumes are an important source of $\mathrm{P}$ with a high $\mathrm{P}:$ Ca ratio so that when this is taken into account as in the NEAP algorithm their overall contribution to dietary acidity would be expected to become more neutral. Food combination is also a very important aspect of acid-base balance as vegetables including potatoes which are alkali generating tend to be eaten with meat, fish and eggs which increase dietary acidity. This is particularly the case of the eating patterns of the elderly population.

In the context of diet and bone health median $\mathrm{Ca}$ intakes were slightly above the UK reference nutrient intake of $700 \mathrm{mg} / \mathrm{d}$ but the wide variation meant that considerable numbers had intakes below this. However, attempting to interpret the inter-relationships between intakes of $\mathrm{Ca}$, phosphate, milk/ yoghurt and cheese and acidity is complicated by the sex differences in the results. Such inter-relationships are no doubt influenced by food patterns in terms of the association between food types. However, a more detailed analysis of the individual food items milk, yoghurt and dairy desserts did not account for the sex differences as described above. Thus for women dietary acidity appears independent of intakes of $\mathrm{Ca}$, milk, yoghurt and cheese. This is in contrast to the report for UK teenage girls and boys ${ }^{(27)}$. For men, however, while milk intakes were not associated with acidity, increasing $\mathrm{Ca}$ and cheese intakes were. Interestingly, higher intakes of bread, biscuits and cakes were significantly associated with increases in dietary acidity in women, whereas for men this was only the case for bread.

The two algorithms for NEAP were highly correlated, as observed by Prynne et al. ${ }^{(27)}$. However, when compared in the same participants they resulted in very slight but significantly different $(0.8 \mathrm{mEq} / \mathrm{d})$ average values for all subjects. This confirms that the protein: $\mathrm{K}$ algorithm, based on just protein and $\mathrm{K}$, does accurately demonstrate that in this dataset men's diets are more acid than women's through a relatively higher consumption of protein compared with K-containing foods.
There is increasing evidence to support the negative effects of imbalances in acid-base homeostasis and bone loss, skeletal muscle atrophy and nephrolithiasis in the ageing population $^{(4,9,10)}$. Interestingly, Wachman \& Bernstein hypothesised almost 40 years ago that consuming a typical Western diet may result in the lifelong utilisation of the buffer salts found in bone leading to bone fragility and osteoporosis $^{(5)}$. Furthermore, Frassetto et al. ${ }^{(32)}$ have shown that plasma bicarbonate concentration and glomerular filtration rate with increasing age causes these parameters to fall whereas blood hydrogen ion concentrations increase with age. This in turn leads to an increasingly worsening lowgrade metabolic acidosis and is reflective of increases in dietary acidity. If the acid-base/skeleton theory is to be believed $^{(7,33)}$ the finding of the present study has important implications regarding advocating dietary acid-base advice in the ageing population, particularly in elderly women. This could include programmes to increase fruit and vegetable consumption in those participants with the highest estimates of NEAP, because the NDNS of British adults aged 65 years and over has also shown that levels of both these foods are only consumed in modest amounts. Prudence needs to be exercised in participants with low estimates of NEAP, as such diets are generally lacking in protein such as meats, fish and milk and this may be a concern for bone health.

A limitation of the present study is the lack of information within the database on disease states likely to be influenced by acid-base balance such as bone health. Without such data, the degree to which higher net dietary acid intake is a significant factor in health problems in older population groups will remain poorly understood. Future studies should address this question. It would also be interesting to look at the effects of both food preparation and wholegrain $v$. refined grains on NEAP and is certainly an area of future research. Future work to confirm the prediction value for $\mathrm{OA}$ from surface area in population groups is needed where shape, overall size and body composition are changing as with the agerelated changes in the current population.

In summary, these analyses provide an insight into the acidgenerating potential of the diet of the UK elderly population, showing the diet to be rich in dietary acid precursors, higher in men than women, increasing with age and higher in a more Northerly location. Such trends may also be found in other industrialised countries with similar diets and, in turn, may have important consequences in this vulnerable group.

\section{Acknowledgements}

The authors would like to formally acknowledge and thank the British Journal of Nutrition review process for considerably strengthening our manuscript. The authors also wish to thank the Economic and Social Data Service (ESDS), University of Essex, Wivenhoe Park, Colchester, Essex CO4 3SQ, UK for providing the NDNS dataset of British adults aged 65 years and over.

The present study was sponsored by a Research Council scholarship from the University of Surrey. S. A. L.-N. would like to declare that she is principal investigator on a grant from Glaxo-SmithKline looking at the dietary alkali content of one of their products. H. M. M. would like to declare that she is expert consultant on the Glaxo-SmithKline grant. 
No other authors have any conflicts of interest to declare. R. H. T. G. was responsible for data evaluation and analysis, and drafting the manuscript. S. A. L.-N. contributed to study design, data analysis and manuscript drafting. D. J. M. and J. E. B. critically appraised the manuscript (drafts and final version). H. M. M. also contributed to the design of the study and manuscript draft. D. P. L. was responsible for data interpretation and critical discussion of statistical analysis. L. A. F. and T. R. gave expert advice regarding the calculation models used, as well as critical discussion of analysis and manuscript.

\section{References}

1. Greenhaff PL, Gleeson M \& Maughan RJ (1988) Diet-induced metabolic acidosis and the performance of high intensity exercise in man. Eur J Appl Physiol Occup Physiol 57, 583-590.

2. Remer T, Dimitriou T \& Manz F (2003) Dietary potential renal acid load and renal net acid excretion in healthy, free-living children and adolescents. Am J Clin Nutr 77, 1255-1260.

3. Manz F (2001) History of nutrition and acid-base physiology. Eur J Nutr 40, 189-199.

4. Mitch WE \& Du J (2004) Cellular mechanisms causing loss of muscle mass in kidney disease. Semin Nephrol 24, 484-487.

5. Wachman A \& Bernstein DS (1968) Diet and osteoporosis. Lancet i, 958-959.

6. Barzel US (1995) The skeleton as an ion exchange system: implications for the role of acid-base imbalance in the genesis of osteoporosis. J Bone Miner Res 10, 1431-1436.

7. Arnett T (2003) Regulation of bone cell function by acid-base balance. Proc Nutr Soc 62, 511-520.

8. Arnett TR \& Dempster DW (1986) Effect of pH on bone resorption by rat osteoclasts in vitro. Endocrinology 119, 119-124.

9. Frassetto L, Morris RC Jr \& Sebastian A (1997) Potassium bicarbonate reduces urinary nitrogen excretion in postmenopausal women. J Clin Endocrinol Metab 82, 254-259.

10. Frassetto LA, Lanham-New SA, Macdonald HM, Remer T, Sebastian A, Tucker KL \& Tylavsky FA (2007) Standardizing terminology for estimating the diet-dependent net acid load to the metabolic system. J Nutr 137, 1491-1492.

11. Frassetto LA, Todd KM, Morris RC Jr \& Sebastian A (1998) Estimation of net endogenous noncarbonic acid production in humans from diet potassium and protein contents. Am J Clin Nutr 68, 576-583.

12. Remer T \& Manz F (1994) Estimation of the renal net acid excretion by adults consuming diets containing variable amounts of protein. Am J Clin Nutr 59, 1356-1361.

13. Remer T \& Manz F (1995) Potential renal acid load of foods and its influence on urine pH. J Am Diet Assoc 95, 791-797.

14. Finch S, Doyle W, Lowe C, Bates CJ, Prentice A, Smithers G \& Clarke PC (1998) National Diet and Nutrition Survey: People Aged 65 Years and Over. London: HMSO.

15. Goldberg GR, Black AE, Jebb SA, Cole TJ, Murgatroyd PR, Coward WA \& Prentice AM (1991) Critical evaluation of energy intake data using fundamental principles of energy physiology. Eur J Clin Nutr 45, 569-581.
16. James WPT \& Schofield EC (1990) Human Energy Requirements: A Manual for Planners and Nutritionists. Oxford: Oxford Medical Publications.

17. Bates CJ, Prentice A, Cole TJ, van der Pols JC, Doyle W, Finch S, Smithers G \& Clarke PC (1999) Micronutrients: highlights and research challenges from the 1994-5 National Diet and Nutrition Survey of people aged 65 years and over. Br J Nutr 82, 7-15.

18. Kleinman JG \& Lemann J (1987) Acid Production, in Clinical Disorders of Fluid and Electrolyte Metabolism. New York: McGraw-Hill.

19. DuBois D \& DuBois EF (1916) A formula to estimate the approximate surface area if height and weight be known. Arch Intern Med 17, 863-871.

20. Department of Health (1991) Dietary Reference Values for Food Energy and Nutrients for the United Kingdom. Report of the Panel on Dietary Reference Values of the Committee on Medical Aspects of Food Policy. London: HM Stationery Office.

21. Berkemeyer S \& Remer T (2006) Anthropometrics provide a better estimate of urinary organic acid anion excretion than a dietary mineral intake-based estimate in children, adolescents, and young adults. $J$ Nutr 136, 1203-1208.

22. Hood VL \& Tannen RL (1998) Protection of acid-base balance by $\mathrm{pH}$ regulation of acid production. $N$ Engl J Med 339, 819-826.

23. Lennon EJ, Lemann J Jr \& Litzow JR (1966) The effects of diet and stool composition on the net external acid balance of normal subjects. J Clin Invest 45, 1601-1607.

24. Kurtz I, Maher T, Hulter HN, Schambelan M \& Sebastian A (1983) Effect of diet on plasma acid-base composition in normal humans. Kidney Int 24, 670-680.

25. Rylander R, Remer T, Berkemeyer S \& Vormann J (2006) Acid-base status affects renal magnesium losses in healthy, elderly persons. $J$ Nutr 136, 2374-2377.

26. Frassetto LA, Todd KM, Morris RC Jr \& Sebastian A (2000) Worldwide incidence of hip fracture in elderly women: relation to consumption of animal and vegetable foods. J Gerontol A Biol Sci Med Sci 55, M585-M592.

27. Prynne CJ, Ginty F, Paul AA, Bolton-Smith C, Stear SJ, Jones SC \& Prentice A (2004) Dietary acid-base balance and intake of bone-related nutrients in Cambridge teenagers. Eur J Clin Nutr 58, 1462-1471.

28. Lemann J Jr (1999) Relationship between urinary calcium and net acid excretion as determined by dietary protein and potassium: a review. Nephron 81, Suppl. 1, 18-25.

29. Black AE, Prentice AM, Goldberg GR, Jebb SA, Bingham SA, Livingstone MB \& Coward WA (1993) Measurements of total energy expenditure provide insights into the validity of dietary measurements of energy intake. J Am Diet Assoc 93, 572-579.

30. Buclin T, Cosma M, Appenzeller M, Jacquet AF, Decosterd LA, Biollaz J \& Burckhardt P (2001) Diet acids and alkalis influence calcium retention in bone. Osteoporos Int 12, 493-499.

31. Blatherwick NR (1914) The specific role of foods in relation to the composition of the urine. Arch Intern Med 14, 419-450.

32. Frassetto LA, Morris RC Jr \& Sebastian A (1996) Effect of age on blood acid-base composition in adult humans: role of age-related renal functional decline. Am J Physiol 271, F1114-F1122.

33. Bushinsky DA (2001) Acid-base imbalance and the skeleton. Eur J Nutr 40, 238-244. 